\title{
Unit of Electric Permittivity
}

National Cancer Institute

\section{Source}

National Cancer Institute. Unit of Electric Permittivity. NCI Thesaurus. Code C68788.

A unit for measurement of the ability of a material to resist the formation of an electric field within it. 